\title{
2-tert-butyl-1,4-benzoquinone Induces Apoptosis in Chronic Myeloid Leukemia Cells Resistant to Imatinib via Inducing Caspase-Dependent Bcr- Abl Downregulation
}

\author{
Xianping Shi ${ }^{1}$, Xiaoying Lan ${ }^{1}$, Xiaofen Li ${ }^{1}$, Xin Chen ${ }^{1}$, Bing Z. Carter ${ }^{2}$, Xuejun Wang ${ }^{1,3}$ and Jinbao Liu $^{1 *}$
}

${ }^{1}$ State Key Lab of Respiratory Disease, Protein Modification and Degradation Lab, Departments of Pathophysiology and Biochemistry, Guangzhou Medical University, Guangdong 510182, China

${ }^{2}$ Section of Molecular Hematology and Therapy, Department of Stem Cell Transplantation and Cellular Therapy, The University of Texas M.D. Anderson Cancer Center, Houston, TX 77030, USA

${ }^{3}$ Division of Basic Biomedical Sciences, Sanford School of Medicine of the University of South Dakota, Vermillion, South Dakota 57069, USA

\begin{abstract}
Bcr-Abl-T315I mutation-induced imatinib (IM) resistance remains a major challenge for clinical management of chronic myelogenous leukemia (CML). Therefore it is imperative to search for novel agents to overcome IMresistance. 2-Tert-butyl-1,4-benzoquinone (TBQ) is an oxidation product of 2-tert-Butylhydroquinone (TBHQ) which has been developed as a food additive and proves to be a strong antioxidant. Previous studies showed that TBQ has cytotoxic effect on different types of neoplastic cells. Our recent study confirmed that TBQ induced apoptosis and cell proliferation inhibition in CML cells and inhibited the growth of IM-resistant primary monocytes from CML patients. Here we further report that TBQ-induced caspase activation is required for the downregulation of Bcr-Abl and apoptotic cell death in both IM-resistant and IM-sensitive CML cells. These findings suggest an alternative strategy to overcome IM resistance by enhancing Bcr-Abl downregulation with TBQ.
\end{abstract}

Keywords: 2-tert-butyl-1,4-benzoquinone; Apoptosis; Chronic myelogenous leukemia; Imatinib resistance; Bcr-Abl

\section{Introduction}

The dysregulated activity of the Bcr-Abl tyrosine kinase resulting from the $t(9 ; 22)$ chimeric chromosomal translocation is necessary for the transformed phenotype of chronic myelogenous leukemia (CML) cells [1-3]. The Bcr-Abl fusion oncoprotein constitutively activates mitogenic signaling pathways such as MAPK/ERK cascade, PI3K/Akt, and STATs pathways [4-6] Activation of these pathways in Bcr-Abl expressing cells results in increased expression of several antiapoptotic proteins, such as $\mathrm{Bcl} 2, \mathrm{Mcl}-1, \mathrm{XIAP}$, thereby conferring cell survival advantage [7-9]. The Bcr-Abl tyrosine kinase has been considered an important target for CML therapeutics [10]. Imatinib mesylate (IM) was developed as an Abl-selective tyrosine kinase inhibitor in 1993 and showed significant efficacy in improving drug response rate and survival rate in CML chronic phase [11]. However, despite its impressive efficacy, disease relapse has been observed after initial response to IM $[12,13]$. Among the mechanisms proposed so far to account for the IM resistance, amplification and mutation of Bcr-Abl are believed to be the predominant ones. T315I mutation, the most stubborn point mutation, accounts for about $20 \%$ of mutations within the Abl kinase domain [14-16]. To overcome this resistance, second-generation Abl kinase inhibitors such as nilotinib, dasatinib, and INNO-406 have been developed and are effective against all but the T315I mutation [17-19] Hence, additional strategies to overcome the IM resistance are required. The aim of the present study was to identify a novel compound that can inhibit Bcr-Abl activity in IM-resistant CML cells.

2-Tert-butyl-1,4-benzoquinone (TBQ) is a strong oxidant derived from oxidation of 2-tert-Butylhydroquinone (TBHQ), which is used as a food additive in oils, fat and meat products, primarily to prevent rancidity. Metabolically, TBHQ is formed from 3-tertbutyl-4-hydroxyanisole (BHA), another widely used food additive, by O-demethylation [20,21]. Studies have shown that TBQ at a low dose induced DNA damage, resulting in the formation of 8-hydroxydeoxyguanosine in thymus DNA due to the generation of reactive oxygen species (ROS) such as superoxide anion and hydrogen peroxide [22-24]. Recent studies show that TBQ has a strong cytotoxic effect on several types of neoplastic cells $[25,26]$. The cytotoxic activity of TBQ along with its relative safe profile in humans warrants the translational potential of TBQ in clinical cancer therapy. However, to our knowledge, whether TBQ could overcome IM-resistance has not been reported.

In the present study, we investigated the antineoplastic effects of TBQ in both CML cell lines and mononuclear cells from CML patients, including those resistant to IM-based therapies. Our results compellingly indicate that TBQ can efficiently overcome IM-resistance through downregulation of Bcr-Abl.

\section{Materials and Methods}

\section{Chemicals}

2-Tert-butyl-1,4-benzoquinone (TBQ), annexin $\mathrm{V}$, propidium iodide (PI) and rhodamine-123 were obtained from Sigma-Aldrich (St. Louis, MO). z-VAD-fmk was from BD Biosciences (San Jose, CA). Antibodies against c-Abl (C-19), Mcl-1 (S-19), caspase-3, -8 were from Santa Cruz Biotechnology (Santa Cruz, CA). Antibodies against poly (ADP)-ribose polymerase (PARP, clone 4C10-5) were from $\mathrm{BD}$ Biosciences. Antibodies against phospho-c-Abl at Y245, phosphoErk1/2 (T202/Y204), Erk1/2, phospho-Akt, Akt, Bcl-2 and XIAP were from Cell Signaling Technology (Beverly, MA). Antibodies against phospho-STAT5A/B (Y694/Y699, clone 8-5-2) and STAT5 were from

*Corresponding author: Jinbao Liu, Protein modification and Degradation Lab, Department of Pathophysiology, Guangzhou Medical University, Guangzhou, Guangdong 510182, China, Tel: +8620-81340720; Fax: +8620-81340542; E-mail jliu@gzhmu.edu.cn

Received November 11, 2014; Accepted December 10, 2014; Published December 12, 2014

Citation: Shi X, Lan X, Li X, Chen X, Carter BZ, et al (2014) 2-tert-butyl-1,4 benzoquinone Induces Apoptosis in Chronic Myeloid Leukemia Cells Resistant to Imatinib via Inducing Caspase-Dependent Bcr-Abl Downregulation. Med chem 4 786-790. doi:10.4172/2161-0444.1000231

Copyright: (c) 2014 Shi X, et al. This is an open-access article distributed under the terms of the Creative Commons Attribution License, which permits unrestricted use, distribution, and reproduction in any medium, provided the original author and source are credited. 
Upstate Technology; Enhanced chemiluminescence reagents were purchased from Amersham Biosciences (Piscataway, NJ).

\section{Cell sample collection and cell culture}

The method to culture KBM5 and KBM5-T315I cells were described previously [16]. In brief, KBM5 cell line expressing the 210 $\mathrm{kDa}$ wild-type Bcr-Abl was derived from a female CML patient. The KBM5-T315I cells, harboring a threonine to isoleucine substitution at position 315 of $\mathrm{Abl}$, were originally established by exposure to increasing concentrations of IM and became IM-resistant.

Bone marrow samples of CML patients were obtained from discarded material utilized for routine laboratory tests at the Department of Hematology, Guangzhou First Municipal People's Hospital. The use of these materials is with institutional approval and the permission of the patients and volunteers. A total of 3 patients with CML were recruited. Mononuclear cells were isolated by FicollPaque and cultured in RPMI 1640 medium with 15\% FCS as described previously [16,27].

\section{Western blot analysis}

Whole cell lysates were prepared in RIPA buffer $(1 \times \mathrm{PBS}, 1 \% \mathrm{NP}-$ $40,0.5 \%$ sodium deoxycholate, $0.1 \%$ SDS) supplemented with $10 \mathrm{mM}$ $\beta$-glycerophosphate, $1 \mathrm{mM}$ sodium orthovanadate, $10 \mathrm{mM} \mathrm{NaF}, 1$ $\mathrm{mM}$ phenylmethylsulfonyl fluoride (PMSF), and $1 \times$ Roche Protease Inhibitor Cocktail (Roche, Indianapolis, IN). Western blotting was performed as we previously described [16,27].

\section{Cell viability assay}

MTS assay (CellTiter 96 Aqueous One Solution reagent, Promega) was used to measure cell viability in 96-well plates [27]. Briefly, $2 \times 10^{5} /$ $\mathrm{ml}$ cells in $100 \mu \mathrm{l}$ were treated with TBQ for 48 hours. At 4 hours before cell culture termination, $20 \mu \mathrm{l}$ MTS was added to the well. The absorbance at a wavelength of $490 \mathrm{~nm}$ was measured using a plate reader.

\section{Cell death assay}

In live cell culture condition, $1.0 \%$ PI was added to the culture medium to monitor temporal changes in the incidence of cell death. The PI-positive cells were imaged with fluorescence microscope equipped with a digital camera (Axio Obsever Z1, Zeiss, Germany). In addition, apoptosis in cells treated with TBQ for 12 hours was determined by flow cytometry using Annexin V-fluoroisothiocyanate (FITC) /PI double staining. Cells were collected, washed with binding buffer (Sigma-Aldrich, St. Louis, MO), and then incubated in working solution (100 $\mu$ l binding buffer with $0.3 \mu \mathrm{l}$ Annexin V-FITC and PI) for 15 minutes in dark.

\section{Measurement of mitochondrial membrane potential}

The mitochondrial membrane potential of TBQ-treated and untreated cells were assayed using rhodamine-123 (Sigma-Aldrich, St. Louis, MO) staining. Cells were treated with TBQ for 12 hours and stained with $1 \mu \mathrm{M}$ of rhodamine- 123 for 1 hour at $37^{\circ} \mathrm{C}$. Following the staining, the cells were washed and harvested for either flow cytometry analysis or imaging with an inverted fluorescence microscope.

\section{Statistical analysis}

All experiments were performed at least three times. The results were expressed as Mean \pm SD where applicable. The GraphPad Prism 4.0 software (GraphPad Software) was used for statistical analysis. Analysis of variance (ANOVA) and Student's $t$-test were used to compare the differences between groups. $P$ value less than 0.05 is considered statistically significant.

\section{Results}

\section{TBQ induces cytotoxicity in both Bcr-Abl wild-type and Bcr- Abl-T315I cells}

KBM5 (Bcr-Abl wild-type) cells are IM-sensitive but KBM5-T315I (Bcr-Abl-T315I mutation) cells are resistant to IM [16,27]. MTS assays were performed to evaluate the inhibitory effect of TBQ on the growth of KBM5 and KBM5-T315I cells. Cells were treated with escalating concentrations of TBQ for 48 hours. As shown in Figure 1A, TBQ dosedependently decreased cell viability in KBM5 and KBM5-T315I cells with the $\mathrm{IC}_{50}$ values being $5.45 \mu \mathrm{M}$ and $7.9 \mu \mathrm{M}$, respectively.

We next analyzed the time course of TBQ induction of cell death in Bcr-Abl wild-type and T315I mutant cell lines. KBM5 and KBM5T315I cells were exposed to TBQ followed by PI staining, a time-

\section{A}
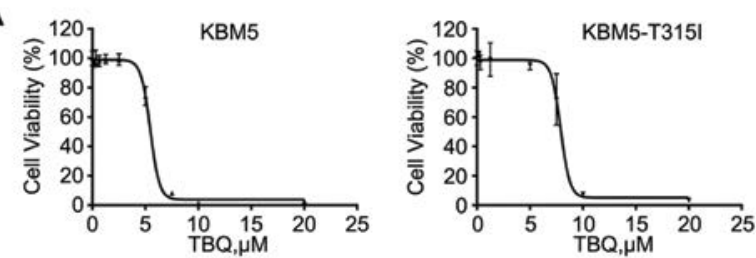

B
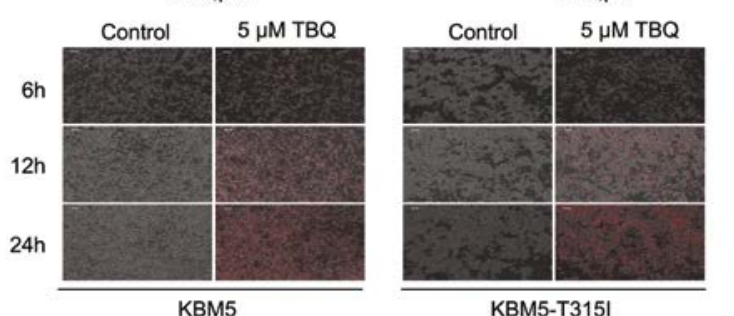

C

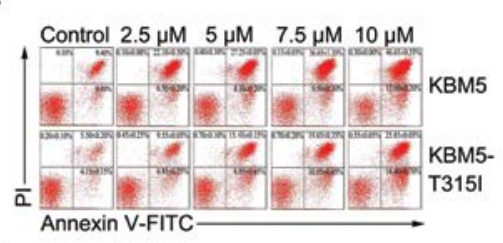

KBM5-T315I

$\mathrm{D}$
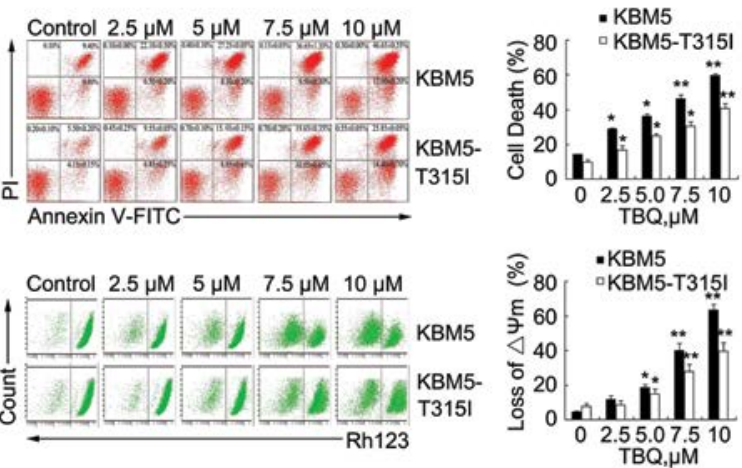

Figure 1: TBQ induces proliferation inhibition and apoptosis of CML cells (A) Dose-response curves of CML cells to TBQ. KBM5 and KBM5-T315 cells were cultured with various concentrations of $T B Q$ for 48 hours. Cell viability was then examined by MTS assay. Graphs represent data from three independent experiments. Mean $\pm S D(n=3)$. (B) TBQ treatment induced cell death in CML cells. KBM5 and KBM5-T315I cells were treated with TBQ in the indicated concentrations for 6,12 or 24 hours. Cell death was detected by $\mathrm{PI}$ staining. Mean $\pm S D(n=3)$. (C) Induction of apoptosis in CML cells by TBQ. KBM5 and KBM5-T315I cells were treated with the indicated concentrations of TBQ for 12 hours; the percentage of cells undergoing apoptosis was determined with Annexin V/PI staining followed by flow cytometry (left). The proportion of apoptotic cells measured by flow cytometry is summarized by the graph at the right side. Mean $\pm \mathrm{SD}, \mathrm{n}=3$; ${ }^{*} \mathrm{P}<0.05$, ${ }^{\star *} \mathrm{P}<0.01$, versus vehicle control. (D) TBQ decreased the mitochondrial membrane potential in KBM5 and KBM5-T315I cells. Cells were treated with $2.5,5,7.5$ or 10.0 $\mu \mathrm{M}$ TBQ for 12 hours; mitochondrial membrane potential was detected using rhodamine-123 staining followed by flow cytometry, Mean $\pm S D(n=3)$, * $P<$ $0.05,{ }^{* *} \mathrm{P}<0.01$, versus vehicle control. 
dependent increase in cell death was observed by recording the PIpositive cells under a fluorescence microscope (Figure 1B). Similarly, exposure of KBM5 and KBM5-T315I cells to escalating concentrations of TBQ resulted in significant increases in AnnexinV/PI-positive cells as detected by flow cytometry analysis (Figure 1C), supporting that TBQ at a reasonably low dose can induce apoptosis in the CML cells. It is well known that mitochondria are the regulating center of apoptosis [28]. As shown in Figure 1D, the mitochondrial membrane potential in both KBM5 and KBM5-T315I cells was remarkably decreased by TBQ treatment, indicating that TBQ treatment leads to loss of mitochondrial membrane integrity.

\section{TBQ induces caspase activation in CML cells}

In order to better understand the anticancer mechanism of TBQ, we next examined TBQ effects on the expression of apoptosis-associated proteins. Western blot analysis showed that TBQ induced the cleavage of PARP in both a dose- and a time-dependent manner in the two CML cell lines. Meanwhile, the precursor forms of caspase- 3 and -8 were decreased, revealing that TBQ may trigger CML cell apoptosis and caspase activation (Figure 2A).

To further investigate the mechanism of TBQ-induced apoptosis, the effect of TBQ on the expression of other apoptosis-related proteins was measured. As shown in Figure 2B, TBQ induced marked decline of anti-apoptotic proteins, including Bcl-2, Mcl-1 and XIAP in both KBM5 and KBM5-T315I cells.

\section{TBQ downregulates Bcr-Abl protein- and inhibits its} downstream signaling

To determine whether the antiproliferative effects of TBQ were
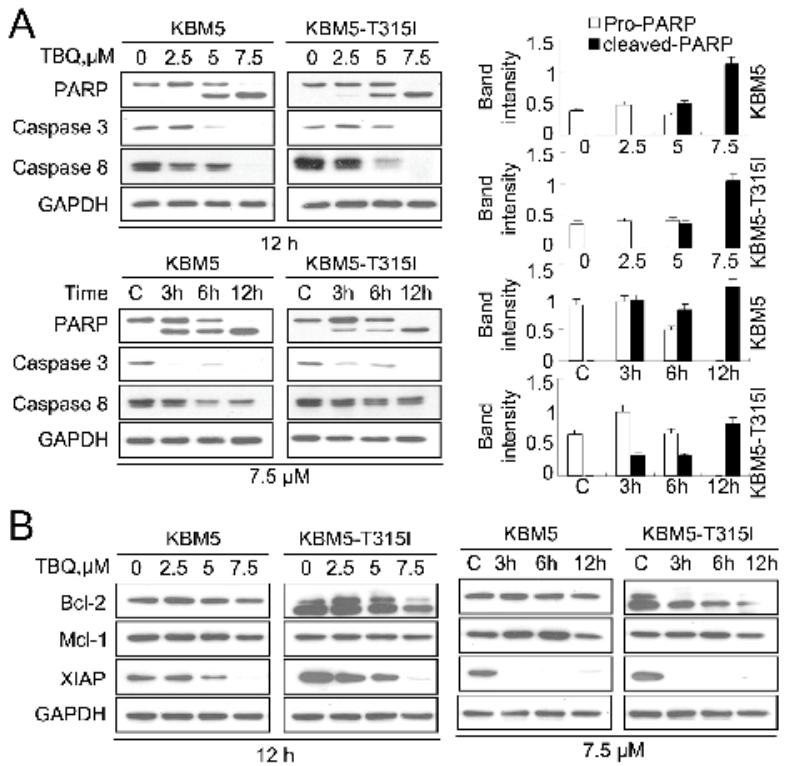

Figure 2. TBQ-induced apoptosis is associated with caspase activation and decreased expression of anti-apoptotic proteins in CML cells.

(A) TBQ induced PARP cleavage and caspase activation in KBM5 and KBM5-T315I cells. Cells were dose- and time-dependently treated with TBQ. PARP and caspase $-3,-8$ were analyzed by western blots. GAPDH was used as a loading control. C: control. The quantitative analyses of western blot results of PARP are summarized in the bar graphs accompanying the representative images, Mean $\pm S D(n=3)$. (B) TBQ decreased the expression of anti-apoptotic proteins in KBM5 and KBM5-T315I cells. Cells were dose- and time-dependently treated with TBQ. The anti-apoptotic proteins $\mathrm{Bcl}-2$, Mcl-1 and XIAP were analyzed by western blot. dependent on the inhibition of $\mathrm{Bcr}-\mathrm{Abl}, \mathrm{Bcr}-\mathrm{Abl}$ protein and its downstream signaling factors were measured using western blot analyses. As shown in Figure 3A, TBQ treatment induced a downregulation of the total and phosphorylated forms of Bcr-Abl proteins in KBM5 and KBM5-T315I cells in both dose- and time-dependent manner. Further analyses displayed that the phosphorylation of STAT5, ERK1/2 and Akt were also significantly decreased in a dose- and timedependent manner with less dramatic changes in the total protein level of ERK1/2. Taken together, our data demonstrate that TBQ induces downregulation of $\mathrm{Bcr}-\mathrm{Abl}$ protein and consequently suppresses the signaling pathway downstream of Bcr-Abl.

\section{Bcr-Abl downregulation relies on caspase-dependent cleavage}

We and others have reported that Bcr-Abl could be cleaved by caspase activation $[27,29]$. To address the mechanism by which TBQ downregulates $\mathrm{Bcr}-\mathrm{Abl}$ protein in $\mathrm{CML}$ cells, we tested the impact of caspase inhibition on Bcr-Abl protein levels in the cell receiving TBQ treatment. We observed that to a large extent, pan-caspase inhibitor $\mathrm{z}$-VAD-fmk blocked TBQ from inducing cell death and the decreases of Bcr-Abl and its downstream signaling proteins (Figure 3B). These results demonstrate that TBQ-induced caspase activation is required for the downregulation of $\mathrm{Bcr}-\mathrm{Abl}$ and of its downstream events.

\section{Ex vivo effects of TBQ on primary monocytes from patients with CML}

The results described above show that TBQ is effective in both
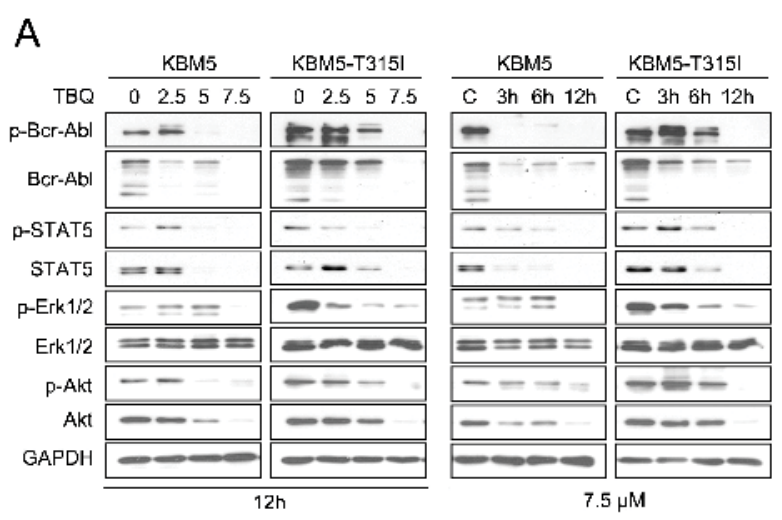

B
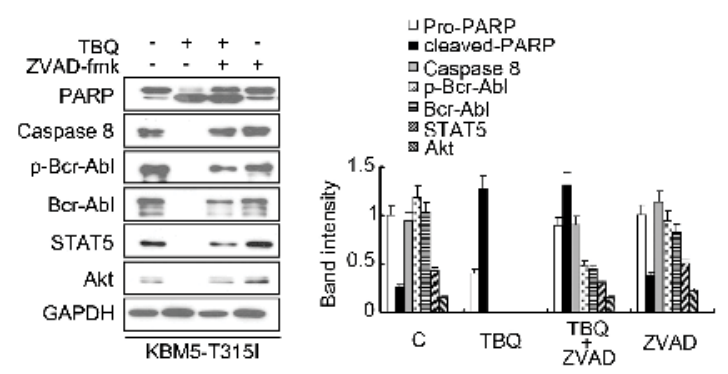

Figure 3. Caspase activation contributes to $T B Q$-induced Bcr-Abl downregulation.

(A) TBQ induced down-regulation of Bcr-Abl and its downstream signaling proteins. KBM5 and KBM5-T315I cells were dose- and time-dependently treated with TBQ. Bcr-Abl and its downstream proteins were detected by western blot analyses. GAPDH was used as a loading control. C: control. (B) Caspase inhibition blocked TBQ from decreasing Bcr-Abl and its downstream signaling proteins. KBM5-T315I cells were treated with $7.5 \mu \mathrm{M} \mathrm{TBQ}$ with/ without caspase inhibitor z-VAD-fmk $(20 \mu \mathrm{M})$ for 12 hours. The total and phosphorylated Bcr-Abl and its downstream proteins were detected by western blot analyses. The quantitative analyses of the western blot results are summarized in the accompanying bar graph, Mean $\pm S D(n=3)$. 
IM-sensitive and -resistant CML cell lines. We next evaluated the ex vivo antineoplastic effect of TBQ on bone marrow mononuclear cells from 3 CML patients (\#3 patient was IM-resistant). The most typical histograms of MTS assay for the cells from 2 patients are shown in Figure 4A. TBQ treatment decreased the cell viability of primary monocytes from CML patients with the $\mathrm{IC}_{50}$ values being 7.83 and 8.28 $\mu \mathrm{M}$, respectively. Furthermore, treatment of TBQ at doses from $5 \mu \mathrm{M}$ to $15 \mu \mathrm{M}$ for 24 hours resulted in significant increases in apoptosis in the monocytes from all $3 \mathrm{CML}$ patients as detected by either PI staining or Annexin V/PI double staining; the most typical images are presented (Figures $4 \mathrm{~B}, 4 \mathrm{C}$ ). These results are consistent with the in vitro inhibitory effect of TBQ on KBM5 and KBM5-T315I cells, indicative of a great potential for use of TBQ to treat CML patients.

\section{Discussion}

The cause of CML is the Philadelphia chromosome carrying the $\mathrm{Bcr}-\mathrm{Abl}$ oncogene $[1,3]$. Imatinib is the first-generation of drugs that specifically target the Bcr-Abl tyrosine kinase. However, it has become

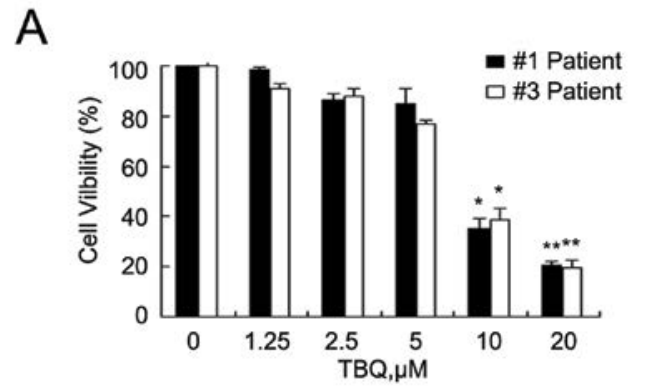

B

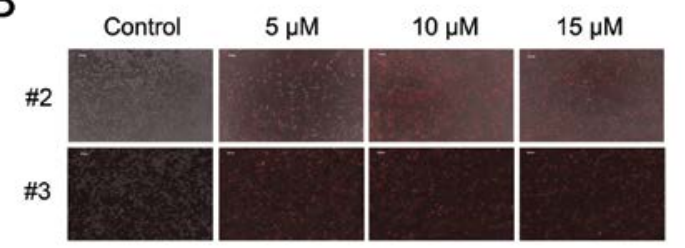

C

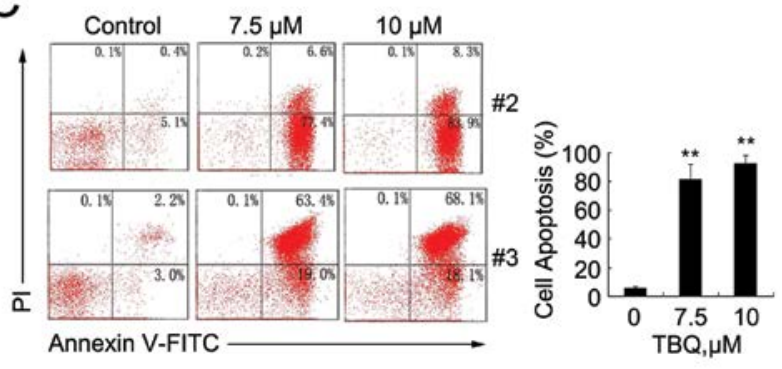

Figure 4. TBQ induces cytotoxicity in cancer cells from CML patients. (A) TBQ induced proliferation inhibition of mononuclear cancer cells. Cancer cells from $3 \mathrm{CML}$ patients were treated with TBQ at the indicated doses for 48 hours and the cell viability was detected by MTS assay. Mean \pm SD $(n=3)$. The most typical histograms of 2 patients are shown. (\#1: IM-sensitive patient; \#3: IM-resistant patient). (B, C) TBQ induces cell death of cancer cells from either IM-sensitive or IM-resistant CML patients. Cancer cells isolated from $3 \mathrm{CML}$ patients were incubated with TBQ for 24 hours, followed by detecting the PI-positive cells under an inverted microscope (B), or staining with Annex in V/PI and cell apoptosis was analyzed by flow cytometry $(C)$. Cell death data from flow cytometry were summarized in the graph shown at the right panel, Mean $\pm S D(n=3)$. The most typical images of 2 patients were shown. (\#2: IMsensitive patient; \#3: IM-resistant patient). ${ }^{*} \mathrm{P}<0.05$, ${ }^{* *} \mathrm{P}<0.01$, versus vehicle control. apparent that a large portion of patients chronically treated with IM develop resistance due to $\mathrm{Bcr}-\mathrm{Abl}$ overexpression or mutations such as T315I, E255K and M351T in the Bcr-Abl kinase domain [11-13]. Importantly, even newer inhibitors (e.g. nilotinib, dasatinib, sunitinib and sorafenib), which can effectively inhibit the phosphorylation of the mutated Bcr-Abl (E255K, M351T), cannot effectively inhibit the T315I mutant Bcr-Abl [30]. Moreover, an aurora kinase inhibitor such as VX-680 [31], MAP kinase inhibitor such as BIRB-796 [32], and ROS promoting agents such as PEITC [33], have been assessed to overcome the problem of the Bcr-Abl T315I mutation but satisfied results have not been derived yet [34,35]. Therefore, innovative treatment has been urgently sought to over-ride T315I mutation, and to promote elimination of Bcr-Abl harboring cells in the patient. Recent data suggest that inhibiting Bcr-Abl expression is a promising approach to overcoming IM resistance.

To search for an alternative therapy for IM-resistant CML, particularly those harboring T315I Bcr-Abl mutation, we evaluated in the present study an antioxidant TBQ, the oxidation product of TBHQ, which was developed as a food additive [20,21]. Recent research has revealed that TBQ has antitumor activities in different type of human cancer cells, including monocytic leukemia U937 cells [25] and lung cancer A549 cells [26]. In the present study, we have demonstrated that TBQ is highly effective in overcoming IM-resistant cancer cells in vitro and in primary monocytes from patients with CML. TBQ dose- and time-dependently decreased cell viability and induced apoptosis in not only wild-type Bcr-Abl or T315I-Bcr-Abl cell lines but also mononuclear cancer cells derived from CML patients that are either IM-resistant or -sensitive in vitro. To our knowledge, this is the first report to show that TBQ is effective against CML cells, including those with the T315I mutation. Furthermore, we have unraveled that TBQ induces cell apoptosis and overcomes IM-resistance in CML cells through Bcr/Abldependent mechanisms. TBQ-induced caspase activation decreased $\mathrm{Bcr}-\mathrm{Abl}$ protein levels (Figure $3 \mathrm{~B}$ ), thereby leading to cell proliferation inhibition and apoptosis. Also, TBQ led to a distinct inhibition of BcrAbl phosphorylation, indicating decreased Abl-kinase activity as well as a pronounced inhibition of phosphorylation of Bcr-Abl downstream targets STAT5, Akt and ERK in both wild-type Bcr-Abl and T315I-BcrAbl cell lines (Figure 3A). The downstream targets of STAT5 responsible for enhanced survival of $\mathrm{Bcr}-\mathrm{Abl}$ cells are involved in the transcription of Mcl-1, XIAP or Bcl-2 [36,37]. Here, we report that TBQ treatment dose- and time-dependently induces down-regulation of anti-apoptotic proteins including Bcl-2, Mcl-1 and XIAP, which leads to the decrease of mitochondrial membrane integrity (Figure 1D), thus inducing the release of cytochrome C and AIF [25,27]. The released apoptotic factors would induce caspase activation, resulting in decreased levels of the precursor forms of caspases- 3 and caspases-8. In addition, it has been reported by others that induction of caspase activity by TBQ was prevented by the addition of GSH [25]. Therefore, the decrease of intracellular GSH induced by TBQ treatment may also contribute to caspase activation by inducing DEVDase activity. It is also apparent that TBQ-triggered caspase activation is responsible for not only the observed PARP cleavage and apoptosis but also the downregulation of $\mathrm{Bcr}-\mathrm{Abl}$ protein because we observed that caspase inhibition prevented TBQ from decreasing Bcr-Abl proteins in both IM-sensitive and IMresistant CML cells.

In conclusion, we demonstrate that TBQ has potent anticancer activity against the cells bearing wild type and T315I mutant Bcr-Abl. Based on the mechanism of action and promising activity of TBQ against IM-resistant CML cells, our results suggest for the first time that TBQ may have clinical benefit for patients with CML, particularly those suffering from IM-resistance. We believe this is a discovery of 
great significance and warrants future clinical investigations because effective measures to overcome the IM-resistance exerted by T315I mutant Bcr-Abl are currently lacking.

\section{Acknowledgements}

This work was supported by the National High Technology Research and Development Program of China (2006AA02Z4B5), NSFC (81272451/H1609, 81472762/H1609); NSFC (81470355/H1616, 81100378, 81272556/H1612) (to X.S.); and partially supported by US NIH grants HL072166 and HL085629 (to X.W.).

\section{References}

1. Witte ON (1993) Role of the BCR-ABL oncogene in human leukemia: fifteenth Richard and Hinda Rosenthal Foundation Award Lecture. Cancer Res 53: 485-489.

2. Ren $R$ (2005) Mechanisms of $B C R-A B L$ in the pathogenesis of chronic myelogenous leukaemia. Nat Rev Cancer 5: 172-183.

3. Melo JV, Barnes DJ (2007) Chronic myeloid leukaemia as a model of disease evolution in human cancer. Nat Rev Cancer 7: 441-453.

4. Gesbert F, Sellers WR, Signoretti S, Loda M, Griffin JD (2000) BCR/ABL regulates expression of the cyclin-dependent kinase inhibitor p27Kip1 through the phosphatidylinositol 3-Kinase/AKT pathway. J Biol Chem 275: 3922339230.

5. Danial NN, Rothman P (2000) JAK-STAT signaling activated by Abl oncogenes. Oncogene 19: 2523-2531.

6. Lugo TG, Pendergast AM, Muller AJ, Witte ON (1990) Tyrosine kinase activity and transformation potency of bcr-abl oncogene products. Science 247: 10791082.

7. Amarante-Mendes GP, McGahon AJ, Nishioka WK, Afar DE, Witte ON, et al. (1998) Bcl-2-independent Bcr-Abl-mediated resistance to apoptosis: protection is correlated with up regulation of $\mathrm{Bcl}-\mathrm{xL}$. Oncogene 16: 1383-1390.

8. Soliera AR, Mariani SA, Audia A, Lidonnici MR, Addya S, et al. (2012) Gfi-1 inhibits proliferation and colony formation of p210BCR/ABL-expressing cells via transcriptional repression of STAT 5 and Mcl-1. Leukemia 26: 1555-1563.

9. Airiau K, Mahon FX, Josselin M, Jeanneteau M, Turcq B, et al. (2012) ABT737 increases tyrosine kinase inhibitor-induced apoptosis in chronic myeloid leukemia cells through XIAP downregulation and sensitizes CD34(+) CD38(-) population to imatinib. Exp Hematol 40: 367-378.

10. Thienelt CD, Green K, Bowles DW (2012) New and established tyrosine kinase inhibitors for chronic myeloid leukemia. Drugs Today (Barc) 48: 601-613.

11. Alvarado Y, Kantarjian H, O'Brien S, Faderl S, Borthakur G, et al. (2009) Significance of suboptimal response to imatinib, as defined by the European LeukemiaNet, in the long-term outcome of patients with early chronic myeloid leukemia in chronic phase. Cancer 115: 3709-3718.

12. Kantarjian HM, Talpaz M, Giles F, O'Brien S, Cortes J (2006) New insights into the pathophysiology of chronic myeloid leukemia and imatinib resistance. Ann Intern Med 145: 913-923.

13. Hofmann WK, Komor M, Wassmann B, Jones LC, Gschaidmeier H, et al. (2003) Presence of the BCR-ABL mutation Glu255Lys prior to STI571 (imatinib) treatment in patients with $\mathrm{Ph}+$ acute lymphoblastic leukemia. Blood 102: 659-661.

14. Druker BJ, Tamura S, Buchdunger E, Ohno S, Segal GM, et al. (1996) Effects of a selective inhibitor of the Abl tyrosine kinase on the growth of Bcr-Abl positive cells. Nat Med 2: 561-566.

15. Shah NP (2005) Loss of response to imatinib: mechanisms and management. Hematology Am Soc Hematol Educ Program .

16. Shi X, Jin Y, Cheng C, Zhang H, Zou W, et al. (2009) Triptolide inhibits Bcr-Abl transcription and induces apoptosis in STI571-resistant chronic myelogenous leukemia cells harboring T315I mutation. Clin Cancer Res 15: 1686-1697.

17. Morinaga K, Yamauchi T, Kimura S, Maekawa T, Ueda T (2008) Overcoming imatinib resistance using Src inhibitor CGP76030, Abl inhibitor nilotinib and Abl/ Lyn inhibitor INNO-406 in newly established K562 variants with BCR-ABL gene amplification. Int J Cancer 122: 2621-2627.

18. Kaur P, Feldhahn N, Zhang B, Trageser D, Müschen M, et al. (2007) Nilotinib treatment in mouse models of P190 Bcr/Abl lymphoblastic leukemia. Mol Cancer 6: 67.

19. Talpaz M, Shah NP, Kantarjian H, Donato N, Nicoll J, et al. (2006) Dasatinib in imatinib-resistant Philadelphia chromosome-positive leukemias. N Engl J Med 354: 2531-2541.

20. Williams GM, McQueen CA, Tong C (1990) Toxicity studies of butylated hydroxyanisole and butylated hydroxytoluene. I. Genetic and cellular effects. Food Chem Toxicol 28: 793-798.

21. Armstrong KE, Wattenberg LW (1985) Metabolism of 3-tert-butyl-4hydroxyanisole to 3-tert-butyl-4,5-dihydroxyanisole by rat liver microsomes. Cancer Res 45: 1507-1510.

22. Jin W, Kong J, Wang H, Wu J, Lu T, et al. (2011) Protective effect of tertbutylhydroquinone on cerebral inflammatory response following traumatic brain injury in mice. Injury 42: 714-718.

23. Nagai F, Okubo T, Ushiyama K, Satoh K, Kano I (1996) Formation of 8-hydroxydeoxyguanosine in calf thymus DNA treated with tertbutylhydroquinone, a major metabolite of butylated hydroxyanisole. Toxicol Lett 89: 163-167.

24. Pérez-Rojas JM, Guerrero-Beltrán CE, Cruz C, Sánchez-González DJ Martínez-Martínez CM, et al. (2011) Preventive effect of tert-butylhydroquinone on cisplatin-induced nephrotoxicity in rats. Food Chem Toxicol 49: 2631-2637.

25. Okubo T, Yokoyama Y, Kano K, Kano I (2003) Cell death induced by the phenolic antioxidant tert-butylhydroquinone and its metabolite tert-butylquinone in human monocytic leukemia U937 cells. Food Chem Toxicol 41: 679-688.

26. Eskandani M, Hamishehkar H, Ezzati Nazhad Dolatabadi J (2014) Cytotoxicity and DNA damage properties of tert-butylhydroquinone (TBHQ) food additive. Food Chem 153: 315-320.

27. Shi X, Chen X, Li X, Lan X, Zhao C, et al. (2014) Gambogic acid induces apoptosis in imatinib-resistant chronic myeloid leukemia cells via inducing proteasome inhibition and caspase-dependent Bcr-Abl downregulation. Clin Cancer Res 20: 151-163.

28. Hisatomi T, Nakao S, Murakami Y, Noda K, Nakazawa T, et al. (2012) The regulatory roles of apoptosis-inducing factor in the formation and regression processes of ocular neovascularization. Am J Pathol 181: 53-61.

29. Di Bacco AM, Cotter TG (2002) p53 expression in K562 cells is associated with caspase-mediated cleavage of $\mathrm{C}-\mathrm{ABL}$ and $\mathrm{BCR}-\mathrm{ABL}$ protein kinases. $\mathrm{Br} \mathrm{J}$ Haematol 117: 588-597.

30. Beyazit Y, Kekilli M, Haznedaroglu IC (2010) Second-generation BCR-ABL kinase inhibitors in CML. N Engl J Med 363: 1673.

31. Cheetham GM, Charlton PA, Golec JM, Pollard JR (2007) Structural basis for potent inhibition of the Aurora kinases and a T315I multi-drug resistant mutant form of Abl kinase by VX-680. Cancer Lett 251: 323-329.

32. Pargellis C, Tong L, Churchill L, Cirillo PF, Gilmore T, et al. (2002) Inhibition of p38 MAP kinase by utilizing a novel allosteric binding site. Nat Struct Biol 9: 268-272.

33. Zhang H, Trachootham D, Lu W, Carew J, Giles FJ, et al. (2008) Effective killing of Gleevec-resistant CML cells with $\mathrm{T} 315 \mathrm{I}$ mutation by a natural compound PEITC through redox-mediated mechanism. Leukemia 22: 1191-1199.

34. Young MA, Shah NP, Chao LH, Seeliger M, Milanov ZV, et al. (2006) Structure of the kinase domain of an imatinib-resistant Abl mutant in complex with the Aurora kinase inhibitor VX-680. Cancer Res 66: 1007-1014.

35. Giles FJ, Cortes J, Jones D, Bergstrom D, Kantarjian H, et al. (2007) MK-0457, a novel kinase inhibitor, is active in patients with chronic myeloid leukemia or acute lymphocytic leukemia with the T315I BCR-ABL mutation. Blood 109: 500-502.

36. Warsch W, Kollmann K, Eckelhart E, Fajmann S, Cerny-Reiterer S, et al. (2011) High STAT5 levels mediate imatinib resistance and indicate disease progression in chronic myeloid leukemia. Blood 117: 3409-3420.

37. Nelson EA, Walker SR, Weisberg E, Bar-Natan M, Barrett R, et al. (2011) The STAT5 inhibitor pimozide decreases survival of chronic myelogenous leukemia cells resistant to kinase inhibitors. Blood 117: 3421-3429. 